\title{
Medievalista
}

Online

$28 \mid 2020$

Número 28

os legistas na afirmação da nova dinastia

\section{De João das Regras ao Conselho Régio}

os legistas na afirmação da nova dinastia

From João das Regras to the Royal Council: men of law in the affirmation of the new dinasty

\section{Armando Luís de Carvalho Homem}

\section{(2) OpenEdition}

\section{Journals}

\section{Edição electrónica}

URL: http://journals.openedition.org/medievalista/3302

DOI: $10.4000 /$ medievalista.3302

ISSN: 1646-740X

Editora

Instituto de Estudos Medievais - FCSH-UNL

\section{Edição impressa}

Paginação: 67-86

Refêrencia eletrónica

Armando Luís de Carvalho Homem, «De João das Regras ao Conselho Régio», Medievalista [Online], 28 | 2020, posto online no dia 01 julho 2020, consultado o 23 março 2021. URL: http://

journals.openedition.org/medievalista/3302 ; DOI: https://doi.org/10.4000/medievalista.3302

Este documento foi criado de forma automática no dia 23 março 2021.

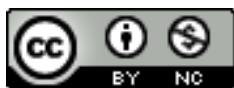

Mediavalista está licenciado com uma Licença Creative Commons - Atribuição-NãoComercial 4.0 Internacional. 
os legistas na afirmação da nova dinastia

De João das Regras ao Conselho

Régio

os legistas na afirmação da nova dinastia

From João das Regras to the Royal Council: men of law in the affirmation of the new dinasty

Armando Luís de Carvalho Homem

\section{3 e depois...: as instituições e os indivíduos}

1 Começarei por uma ideia que anteriormente expus já, mas em que creio não ser demais insistir: o desfecho de 1383-1385 não é propriamente revolucionário em termos de estritos quadros institucionais do poder régio. Com efeito, o organograma da oficialidade burocrática joanina reproduz no essencial aquilo que se fora esboçando entre as décadas de 30 e de 70 , reinando os três últimos monarcas da dinastia fundadora. E significativo é, a tal respeito, o 'desencontro' revelado entre as reivindicações dos artigos 2. e 3.. dos Capitulos Gerais das Cortes de Coimbra e as respectivas respostas do Rei:

2 - Assim, no primeiro dos mencionados artigos, os povos reivindicam para o regimento do que chamam o Conselho régio a existência de um ofício de Chancelaria, outro de Tesouraria, outro do livramento da Fazenda e um último do livramento das graças; o articulado mostra um conhecimento ténue da orgânica existente à data da morte de D. Fernando, ao omitir a existência de ofícios como o de Corregedor da Corte (que vinha dos tempos finais de Afonso IV) e o de Vedor da Fazenda (remontando ao terminus da década de 1360), e isto para já não falar dos escrivães vários, maxime o da Puridade;

3 - a resposta régia é algo 'esquiva', escudando-se em expressões tais como "El [o Rei] dara carrego a estes que ham de estar em seu Conselho que muito melhor sabem fazer como ajam introduzir em no Conselho os negocios e cousas que se ouverem de Livrar", e referindo sequentemente os Vedores da Fazenda para os feitos respectivos; 
4 - quanto ao artigo 3., de menor importância no contexto, prende-se com a reivindicação da existência, em Lisboa, de dois ouvidores, com competência tanto cível quanto criminal na área da urbe e do bispado, e do Chanceler; complementarmente se pede a existência de casas de Justiça em Évora e em Coimbra, com competência, respectivamente, a Sul e a Norte do Tejo;

5 - a resposta, uma vez mais, patenteia a desactualização do requerido: se o Rei concorda com a territorialização das Justiças nos moldes pedidos, já considera escassos dois oficiais para livramento dos feitos de Justiça, subindo o seu número para três, em articulação com o Chanceler ${ }^{1}$.

6 Ou seja: reivindicações não plenamente assentes na realidade próxima-passada das instituições, respostas esquivas, ambíguas (v.g. pelo reiterado uso do termo "Conselho") e não propriamente expressantes de qualquer programa régio para os órgãos do poder; o que, note-se, nada tem de surpreendente em Cortes.

\section{Meio século de reinado como factor de institucionalização das carreiras burocráticas: as três gerações dos oficiais joaninos}

7 Mas se da orgânica institucional passarmos aos oficiais concretos o panorama difere. Desde logo por uma circunstância que se prende ao simples fluir das existências: vivendo até meio da casa dos 70, D. João I terá o mais longo reinado da Idade Média portuguesa, de praticamente meio século; apenas D. Dinis, com 46 régios anos, dele se aproxima. Tal meio século, ainda por cima sem situações de ruptura que se não prendam à simples caducidade biológica das gerações, tem desde logo uma consequência e permite, por outro lado, dar-nos conta de um facto primacial em termos de evolução das instituições:

8 - Assim, e em primeiro lugar, uma consequência: os oficiais joaninos vão normalmente permanecer em funções até ao fim da existência ou até que a falta de saúde ou de boa forma física (v.g., a capacidade para montar a cavalo, no quadro de uma Corte itinerante) os impeçam de continuar no ofício; e assim poderemos neste reinado, a bem dizer pela vez primeira, dar-nos conta da sucessão de três gerações de servidores do aparelho burocrático da Coroa: 1384-ca. 1405; ca. 1405-ca. 1420; e ca. 1420 ss.

9 - Em segundo lugar uma constatação de facto: Trezentos havia sido ainda um tempo de fragilidade dos ofícios régios, sendo mesmo problemático o poder falar-se de carreiras burocráticas; situações de mudança de reinado, de guerra, de crise política, de mutações na Corte eram normalmente o suficiente para desencadear uma substituição, radical ou acentuada, do pessoal da Chancelaria; aliás, pode dizer-se que o século XIV conheceu uma única transição de reinado qualificável como normal: a de D. Pedro I para D. Fernando. Ora, Quatrocentos vai afirmar-se, logo em tempos joaninos, como um tempo de desempenhos da oficialidade mais longos e cada vez mais qualificáveis como carreiras, situação que poderá dizer-se consolidada em tempos manuelinos, sem embargo, até lá, da complexidade, por exemplo, dos anos 1438-1449 e 1480-1483; mas a verdade é que percursos da oficialidade estendendo-se por mais de duas ou de três décadas, clara raridade até então, tendem a tornar-se algo de relativa e crescentemente corrente e normal. 

uma ideia já exposta: continuidade, portanto, de uma orgânica institucional, mas desempenho dos ofícios predominantemente por indivíduos sem antecedentes (ou com escassos antecedentes) no serviço régio. De facto, dos 16 oficiais em funções nos tempos terminais de D. Fernando, 12 desaparecem definitivamente da cena pública, havendo supletivamente a ter em conta 2 casos de continuidade quase linear e mais 2 de afastamento com ulterior reintegração, sendo que num destes casos o intervalo de funções é de 8 anos.

11 Quanto ao total de 24 oficiais que vão estar em funções no período 1384-1395, uma primeira e reiterada observação diz respeito à sua falta de antecedentes pessoais no serviço régio (apenas, pontualmente, no serviço do município de Lisboa). Homens novos, portanto, e até a mais de um título, já que de um modo geral bem poderiam ser mais jovens ao entrar no serviço do Rei do que os seus predecessores. Mas antecedentes de outro tipo podem existir: a circunstância, por demais conhecida, de João das Regras como enteado do antigo oficial petrino e fernandino Álvaro Pais, está longe de ser única. Com efeito, uma investigação já antiga de Maria de Lurdes Rosa ${ }^{2}$ veio chamar a atenção para um total de 4 situações de parentesco entre novos desembargadores de D. João I e antigos oficiais de D. Fernando, os quais já não se encontrariam em funções em 1383, mas antes em situações de alguma 'dissidência' no quadro de uma sociedade de Corte que, e desde os alvores da década de 1370, vivia algumas perturbações, ligadas a circunstâncias que depois poderei particularizar.

- Quase ausentes do Desembargo tardo-fernandino, clérigos e homens de Leis vão ter presença destacada nos tempos subsequentes a 1383. Só que, com uma diferença entre uns e outros: os clérigos, em declínio desde o segundo quartel do século, vão ter, na primeira geração joanina, um dernier souffle, prolongado até meados da década de 1410: é o caso de homens como João Afonso da Azambuja, João Afonso Aranha, Martim Afonso Charneca (ulteriores prelados) ou Rui Lourenço (deão do cabido de Coimbra), entre outros. Depois será o quase desaparecimento no âmbito deste subsector da sociedade política (ainda que, por Quatrocentos adiante, prelados, clérigos e mais pontualmente abades de mosteiros possam ser membros do Conselho, encarregados de missões diplomáticas ou presidentes de um dos tribunais superiores do Reino, entre outras tarefas).

14 - Relativamente aos legistas, não raro, à partida, membros do clero secular, retomam, com a nova dinastia, o caminho ascendente que vinha da quarta década de Trezentos, chegando, nos alvores do novo século, a ultrapassar o terço da totalidade dos oficiais; destaquem-se nomes como o Lic.. Fernão Gonçalves, os irmãos Dr. Diogo Martins e Dr. Gil Martins, o Bach. João Afonso da Azambuja, o escolar João Afonso de Santarém, o Dr. João das Regras, o Dr. Lançarote Esteves, o Dr. Martim Afonso Charneca, o mais tardio Dr. Rui Fernandes ou o Lic.. Rui Lourenço; acrescente-se uma particularidade: a tomada de peso, a partir do início de Quatrocentos, dos doutores em Leis, por vezes formados por Universidades italianas, circunstância iniciada em tempos fernandinos e que agora se retoma, se reforça e se prolonga pela centúria. 


\section{A instância política: rumos do Conselho de D. João I} então o substantivo "conselho" para referir tanto o propriamente dito quanto a burocracia do Desembargo). A este respeito é também conhecido de há muito o artigo 1. dos Capítulos Gerais:

18 - Considerando que o Rei teria "mister" de "boos consilheiros" recrutados nos quatro estados do Reino, propõem os povos a inclusão no Conselho de 14 personalidades, a saber, 2 pelos prelados, 4 pelos fidalgos, 4 pelos letrados e 4 pelos cidadãos de Lisboa, Porto, Coimbra e Évora;

19 - o monarca confirma apenas 6 dos propostos, concretamente D. João Eanes (bispo de Évora), Diogo Lopes Pacheco, Vasco Martins de Melo, o Dr. Gil do Sem, o Dr. João das Regras e o Dr. Martim Afonso Charneca; a resposta refere ainda, em termos algo ambíguos, o(s) representante(s) dos quatro meios urbanos referidosi3 de salientar, entretanto, que nenhum dos nomeados por D. João I possui qualquer antecedente no Conselho fernandino, ainda que um ou outro pontualmente possam ter detido alguma presença na Corte antes de 1383.

Ou seja, o Rei, em última análise, reserva-se o direito de organização do seu Conselho e de designação dos titulares respectivos. A reivindicação em Cortes configuraria um Conselho formado na base da representação "estamental", conceito este de alguma prática na Historiografia jurídica incidente sobre a Idade Média castelhana ${ }^{4}$. Na prática, uma "estamentalização" racionalizada, isto é, mediante a presença, entre os conselheiros, de indivíduos de todas as condições com poder suficiente para ter acesso a tal órgão do Poder, ainda que o estado dos fidalgos tenda para algum predomínio, que os letrados detenham um montante de presenças que o futuro não confirmará e que o estado dos "cidadãos" se paute normalmente por uma presença algo discreta.

Certo é também que os primeiros 10 / 15 anos do reinado joanino conhecerão, com certa naturalidade, um funcionamento mais assíduo do Conselho e em termos de uma certa colegialidade; o órgão de assessoramento político da realeza intervirá então, e por exemplo, previamente à resposta a agravos em Cortes, em questões diplomáticas, em questões jurisdicionais (normalmente quando estão em jogo direitos na matéria de altas individualidades) e até previamente ao despacho de actos de Chancelaria.

Depois... a assiduidade e a colegialidade atenuam-se, as marcas documentais da actuação do Conselho pontualizam-se, a renovação do mesmo permanece limitada até à década de 1410 e só na ponta final do reinado assistiremos a uma reintensificação da sua actividade. Mas verdadeiramente só a diplomacia e as jurisdições manterão peso constante entre os domínios da actividade do Conselho. Mas quando, em fim de reinado, a tal reintensificação ocorrer, já os protagonismos na condução dos destinos do Reino se terão diversificado. 


\section{A afirmação de D. Duarte-Infante (1411 ss.)} demorado, e até algo acidentado (apanhou pelo meio com duas sucessões régias - 1433 e 1438 - e uma regência), e o seu grande protagonista, ao nível dos cumes do poder político, será justamente D. Duarte, sucessivamente enquanto Infante associado à governação e enquanto Rei. textos legais: o códice dos Reservados da Biblioteca Nacional conhecido justamente como Ordenações del-Rei Dom Duarte ${ }^{6}$. Bastante mais apurada na sua organização do que o Livro das Leis e Posturas, esta segunda iniciativa recolectora de leis (num total de 409) apresenta as mesmas arrumadas por reinado e, até certo ponto, sistematizadas por matérias. Remontante, provavelmente, a meados da década de 1430, estas Ordenações 
poderão ter sido 'encomendadas' por D. Duarte como instrumento de consulta dos superiores titulares do Poder - e não para funcionarem como Direito vigente -, poderá o próprio D. Duarte ser o autor da "tauoa" de matérias que as abre, poderão ter integrado a livraria pessoal do segundo dinasta de Avis; e são claramente trabalho preambular às Ordenações Afonsinas ? .

\section{Os homens de Leis e a legitimação da dinastia pela construção do "corpus jurídico-normativo": do Livro das Leis e Posturas às Ordenações Afonsinas}

No processo de, como já disse, cerca de três décadas a elas conducente terão sucessivamente intervenção os oficiais régios João Mendes (Corregedor da Corte), Dr. Rui Fernandes (ao tempo Chanceler), Dr. Lopo Vasques de Serpa (Corregedor de Lisboa) e ainda os Desembargadores Luís Martins e Fernão Rodrigues. Nem todos serão estritamente homens de Leis, i.e., com habilitações jurídicas académicas. Mas faça-se notar que o Corregedor João Mendes, o primeiro a superintender no empreendimento, era à data alguém com quase duas décadas numa área fulcral do serviço régio como era a intervenção em matérias jurisdicionais ${ }^{8}$; e, para além disto, interveniente na elaboração e publicitação da maior parte das leis de D. João I subsequentes a $1402^{9}$.

Processo longo e acidentado, repito. Legislar era algo já remoto no reino de Portugal. Fizera-o, pioneiramente, Afonso II, em 1211, coevamente à Magna Carta inglesa ou a Filipe Augusto de França. Continuadamente se voltara a fazer, e agora sem soluções de continuidade, a partir de Afonso III. O primeiro dinasta de Avis, sem deixar de legislar, iria no entanto presenciar e ajudar a protagonizar os primeiros tentames de compilação dos textos; e, também nisto, os Reis de Portugal foram precoces em termos ocidentais. A iniciativa essencial (1418) deu-se, entretanto, já em fase de protagonismo, outrossim, do herdeiro da Coroa, que nessa matéria será mesmo de protagonismo redobrado. Ou seja, se dos tempos pré-1383 nos ficara mais de um século de normativização régia, a nova dinastia logo iria reforçar a imagem jurídica da realeza pela vertente do rei-legislador ${ }^{10}$, não tanto agora pela criação como pela recolha e sistematização do Direito vigente. Um superavit legitimatório? Sem dúvida. Mas, pelas circunstâncias apontadas, com algumas consequências porventura inesperadas. Assim, as "Ordenações Afonsinas" irão, antes de mais, apresentar, qual reflexo de diferentes mãos organizadoras, um contraste de fundo entre:

31 - Por um lado, o livro I, cujos artigos apresentam aquilo que o jargon histórico-jurídico costuma designar como estilo decretório, i.e., uma abstracção e uma impessoalidade que o aproximam do discurso jurídico que vimos conhecendo a partir de Oitocentos;

32 - e, por outro, os livros II a V, onde nos sucessivos títulos frequentemente se apresenta a genealogia da norma, por vezes a partir de monarcas de Duzentos, e até à forma final, procedimento este, está bem de ver, claramente mais arcaico.

33 Para além disto, e talvez até mais fundamental, o Código Afonsino, em termos de conteúdo, apresenta-se-nos mais como uma compilação e adaptação de sucessivas leis de Duzentos e de Trezentos, bem mais do que um legislar ex novo. E não é por acaso que, mal entradas em vigor, se começa a legislar sobre matérias omissas ou a alterar matérias efectivamente consignadas. Não será, pois, de estranhar que diversos historiadores, para além de apontarem a vigência relativamente efémera das Ordenações 
Afonsinas (1448-1521), questionem a própria intensidade da sua vigência, tendo até em conta o baixo número dos manuscritos quatrocentistas.

Ou seja: a recolha legislativa com o seu minuto zero no ano de 1418 acaba por se revelar uma das circunstâncias responsáveis por um acentuado cristalizar do legado institucional da nossa Idade Média Tardia, sobrevivendo inclusivamente às duas versões (1512-1514 e 1521) da reforma manuelina das Ordenações, para só se deter, verificada em Quinhentos a feição já bem diversa do montante da população do Reino, perante - quem diria? - os impulsos reformadores do monarca predominantemente ainda recordado pela introdução entre nós do Tribunal do Santo Ofício...
A. Ofícios da burocracia régia em tempos joaninos (1384-1433)
1. Chanceler-Mor
2. Escrivão da Puridade
3. Escrivão da Chancelaria
4. Corregedor da Corte
5. Vedores da Fazenda (quatro)
6. Desembargadores (três)
7. Sobrejuízes [cível] (quatro)
8. Ouvidores [crime] (três)
9. Contadores (quatro)

\section{BIBLIOGRAFIA}

Fontes impressas:

LIVRO das Leis e Posturas. Ed. Nuno Espinosa Gomes da SILVA e Maria Teresa Campos RODRIGUES. Lisboa: Faculdade de Direito, 1981.

ORDENAÇÕES AFONSINAS, livs. I-V, reimpr. da ed. de 1792. Lisboa: Fundação Calouste Gulbenkian., 1984.

ORDENAÇÕES DEL-REI Dom Duarte. Ed. Martim de ALBUQUERQUE e Eduardo Borges NUNES. Lisboa: Fundação Calouste Gulbenkian, 1988.

Estudos:

ALBUQUERQUE, Ruy de; ALBUQUERQUE, Martim de - História do Direito Português, 10.̣ ed.. Lisboa: Pedro Ferreira - Artes Gráficas, 1999.

BARROS, Henrique da Gama - Historia da Administração Publica em Portugal nos seculos XII a XV. Ed. Torquato de Sousa SOARES, t. III. Lisboa: Sá da Costa, 1947.

CAETANO, Marcello - A Crise Nacional de 1383-1385. Subsídios para o Seu Estudo. Lisboa / São Paulo: Verbo, [1985]. 
CAETANO, Marcello - História do Direito Português. $4^{a}$ ed., seguida de "Subsídios para a História das fontes de Direito em Portugal no século XVI", textos introdutórios e notas de Nuno Espinosa Gomes da SILVA. Lisboa / São Paulo: Verbo, 2000.

COELHO, Maria Helena da Cruz - D. João I. Rio de Mouro: Círculo de Leitores, 2006.

COELHO, Maria Helena da Cruz; HOMEM, Armando Luís de Carvalho (coord.) - A Génese do Estado Moderno no Portugal Tardo-Medievo (séculos XIII-XV). Lisboa: UAL, 1999.

DIOS, Salustiano de - El Consejo Real de Castilla (1385-1522). Madrid: Centro de Estudios Constitucionales, 1982.

FAVIER, Jean (dir.) - XIV et XV siècles: crises et genèses. Paris: PUF, 1996.

FREITAS, Judite A. Gonçalves de - A Burocracia do "Eloquente" (1433 -1438). Os textos, as normas, as gentes. Cascais: Patrimonia, 1996.

FREITAS, Judite A. Gonçalves de - “Teemos por bem e mandamos”. A Burocracia Régia e os seus oficiais em meados de Quatrocentos (1439-1460). Cascais: Patrimonia, 2001.

GOMES, Rita Costa - A Corte dos Reis de Portugal no final da Idade Média. Lisboa: Difel, 1995.

GRAF, Carlos Eduardo de Verdier - D. João Esteves da Azambuja: exemplo da interligação de poderes (séculos XIV e XV). Porto: Faculdade de Letras da Universidade do Porto, 2011. Tese de mestrado.

GUENÉE, Bernard - L'Occident aux XIV et XV siècles. Les États, 4. e ed. Paris: PUF, 1991.

HESPANHA, António M. - História das Instituições. Épocas medieval e moderna. Coimbra: Almedina, 1982.

HOMEM, Armando Luís de Carvalho - "O Doutor João das Regras no Desembargo e no Conselho Régios (1384-1404). Breves notas". in Estudos de História de Portugal, I. Séculos X-XV. Homenagem a A. H. de Oliveira Marques. Lisboa: Estampa, 1982, pp. 241-253. Reed. in HOMEM, Armando Luís de Carvalho - Portugal nos Finais da Idade Média: Estado, Instituições, Sociedade Política. Lisboa: Livros Horizonte, 1990, pp. 149-158.

HOMEM, Armando Luís de Carvalho - "Uma crise que sai d' "A Crise" ou o Desembargo Régio na década de 1380". Revista de História (Centro de História da UP) 5 (1983-1984), pp. 53-92. Reed. in HOMEM, Armando Luís de Carvalho - Portugal nos Finais da Idade Média: Estado, Instituições, Sociedade Política. Lisboa: Livros Horizonte, 1990, pp. 175-213.

HOMEM, Armando Luís de Carvalho - "Em torno de Álvaro Pais". Estudos Medievais 3/4 (1983/84), pp. 93-130. Reed. in HOMEM, Armando Luís de Carvalho - Portugal nos Finais da Idade Média: Estado, Instituições, Sociedade Política. Lisboa: Livros Horizonte, 1990, pp. 108-148.

HOMEM, Armando Luís de Carvalho - "Conselho Real ou Conselheiros do Rei? A propósito dos ‘Privados' de D. João I”. Revista da Faculdade de Letras [UP]. História, II sér., 4 (1987), pp. 9-68 (Separata, Porto, 1987). Reed. in HOMEM, Armando Luís de Carvalho - Portugal nos Finais da Idade Média: Estado, Instituições, Sociedade Política. Lisboa: Livros Horizonte, 1990, pp. 221-278.

HOMEM, Armando Luís de Carvalho - “A sociedade política joanina (1384-1433): para uma visão de conjunto”. En la España Medieval 12 (1989), pp. 231-241.

HOMEM, Armando Luís de Carvalho - "État, institutions, société politique sous Jean I I et Édouard $\mathrm{I}^{\mathrm{er}}$ (1384-1438) ". Arquivos do Centro Cultural Português 26 (1989), pp. 35-48.

HOMEM, Armando Luís de Carvalho - Portugal nos Finais da Idade Média: Estado, Instituições, Sociedade Política. Lisboa: Livros Horizonte, 1990. 
HOMEM, Armando Luís de Carvalho - O Desembargo Régio (1320-1433). Porto: INIC - Centro de História da Universidade do Porto, 1990.

HOMEM, Armando Luís de Carvalho - "Prelados e Clérigos Régios no meio-século joanino (1384-1433): para uma reapreciação de situações”. in Estudos em Homenagem ao Prof. Doutor Martim de Albuquerque, vol. I. Lisboa - Coimbra: Faculdade de Direito da Universidade de Lisboa - Coimbra Editora, 2010, pp. 205-211.

MARQUES, A. H. de Oliveira - Portugal na crise dos séculos XIV e XV (= Nova História de Portugal, dir. Joel Serrão; A. H. de Oliveira Marques, vol. IV). Lisboa: Presença, 1987.

MATTOSO, José (dir.) - A Monarquia Feudal (1096-1480) (= História de Portugal, dir. José Mattoso, vol. 2). Lisboa: Círculo de Leitores, 1993.

MORENO, Humberto Baquero (coord.) - História de Portugal Medievo: político e institucional. 2 vols. Lisboa: Universidade Aberta, 1995.

NIETO SORIA, José Manuel - Fundamentos ideológicos del poder real en Castilla (siglos XIII-XVI). Madrid: EUDEMA, 1988.

NIETO SORIA, José Manuel (dir.) - Orígenes de la monarquía hispánica: propaganda y legitimación (ca. 1400-1520). Madrid: Dykinson, 1999.

ROSA, Maria de Lurdes - Pero Afonso Mealha. Os bens e a gestão de riqueza de um proprietário leigo do século XIV. Redondo: Patrimonia, 1995.

SILVA, Nuno J. Espinosa Gomes da - História do Direito Português. Fontes de Direito. 4. ․ ed. Lisboa: Fundação Calouste Gulbenkian, 2006.

SOUSA, João Silva de - A Casa Senhorial do Infante D. Henrique. Lisboa: Livros Horizonte, 1990.

TAVARES, Maria José Ferro - “Jaime Cortesão: a Revolução de 1383 e Álvaro Pais”. in Cidadania e História: em homenagem a Jaime Cortesão. Lisboa: Sá da Costa, 1985, pp. 111-125 (“Cadernos da Revista de História Económica e Social", n. ${ }^{\text {os }}$ 6-7).

TORRES SANZ, David - La Administracion Central Castellana en la Baja Edad Media. Valladolid: Universidad de Valladolid, 1982.

VENTURA, Margarida Garcez - Igreja e Poder no século XV. Dinastia de Avis e Liberdades Eclesiásticas. Lisboa: Colibri, 1997.

\section{ANEXOS}

10. Juiz dos feitos de el-Rei (1391 ss.)

B. Oficiais burocratas

1. Primeira geração (1384-ca. 1405)

Álvaro Gonçalves

Álvaro Gonçalves Machado

Bach. João Afonso da Azambuja

João Afonso de Santarém

Dr. João das Regras 
Lourenço Anes Fogaça

Dr. Martim Afonso Charneca

Martim da Maia

Lic.. Rui Lourenço

1. Segunda geração (ca. 1405-ca. 1420)

Álvaro Gonçalves de Freitas

Dr. Diogo Martins

Lic.. Fernão Gonçalves

Dr. Gil Martins

Dr. Gomes Martins

Gonçalo Caldeira

Gonçalo Lourenço de Gomide

João Afonso de Alenquer

João Afonso Aranha

João Mendes

Dr. Lançarote Esteves

Lic. ${ }^{\circ}$ Vasco Gil de Pedroso

3. Terceira geração (ca. 1420 ss.)

Diogo Afonso

Dr. Fernando Afonso da Silveira

D. Fernando da Guerra

Fernão Álvares

Fernão Lopes

João de Alpoim

Luís Martins

Pero Gonçalves Malafaia

Dr. Rui Fernandes

A. Conselheiros de D. João I

1. Nomeados em 1384-1400

Afonso Eanes Nogueira

Diogo Lopes Pacheco

Dr. Gil do Sem 
Gomes Martins de Lemos

Gonçalo Peres

Gonçalo Vasques de Melo

Bach. João Afonso da Azambuja

João Afonso de Santarém

D. João Eanes

João Fernandes Pacheco

Dr. João das Regras

Lourenço Esteves («o Moço»)

Dr. Martim Afonso Charneca

Martim Afonso de Melo

Nuno Álvares Pereira

Vasco Martins de Melo

2. Ulteriores

D. Afonso de Cascais

Aires Gomes da Silva

Álvaro Gonçalves de Ataíde

D. Fernando da Guerra

D. Fernando de Castro

D. Fernando de Noronha

Fernão Álvares

João Gomes da Silva

João Vaz de Almada

Luís Gonçalves Malafaia

Dr. Martim do Sem

Pero Gonçalves Malafaia

\section{NOTAS}

1. Torre do Tombo [TT] - Livro II de Cortes, fls. 1-18; publ. em apêndice, doc. n.o 4, a CAETANO, Marcello - “As Cortes de 1385” [1951], reed.in CAETANO, Marcello - A Crise Nacional de 1383-1385. Subsídios para o Seu Estudo. Lisboa / São Paulo: Verbo, 1985, pp. 109-111. 
2. ROSA, Maria de Lurdes - Pero Afonso Mealha. Os bens e a gestão de riqueza de um proprietário leigo do século XIV. Redondo: Patrimonia, 1995.

3. Fonte cit. supra, nota 1; publ.: CAETANO, Marcello - A Crise Nacional de 1383-1385. Subsídios para o Seu Estudo ..., pp. 108-109.

4. DIOS, Salustiano de - El Consejo Real de Castilla (1385-1522). Madrid: Centro de Estudios Constitucionales, 1982; TORRES SANZ, David - La Administracion Central Castellana en la Baja Edad Media. Valladolid: Universidad de Valladolid, 1982.

5. Livro das Leis e Posturas. Ed. Nuno Espinosa Gomes da Silva e Maria Teresa Campos Rodrigues. Lisboa: Faculdade de Direito, 1971.

6. Ordenações del-Rei Dom Duarte. Ed. Martim de Albuquerque e Eduardo Borges Nunes. Lisboa: Fundação Calouste Gulbenkian. 1988.

7. Veja-se um ponto da situação, com indicações de Fontes e de Bibliografia, em HOMEM, Armando Luís de Carvalho - "Estado moderno e legislação régia: produção e compilação legislativa em Portugal (séculos XIII-XV)”. in COELHO, Maria Helena da Cruz; HOMEM, Armando Luís de Carvalho (coord.) - A Génese do Estado Moderno no Portugal TardoMedievo (séculos XIII-XV). Lisboa: UAL, 1999, pp. 111-130.

8. HOMEM, Armando Luís de Carvalho - O Desembargo Régio (1320-1433). Porto: INIC/CHUP, 1990, pp. 346 e $442-443$.

9. Cf. o trabalho cit. supra, nota 7.

10. NIETO SORIA, José Manuel - Fundamentos ideológicos del poder real en Castilla (siglos XIII-XVI). Madrid: EUDEMA, 1988, pp. 151-164.

\section{RESUMOS}

O organograma da oficialidade burocrática após 1383-1385 reproduz, no essencial, o que se esboçara entre as décadas de 30 e de 70 de Trezentos. Quando se passa aos oficiais concretos o panorama difere, uma vez que se verifica uma acentuada renovação dos burocratas, com destaque para clérigos e homens de Leis. O século XV vai afirmar-se, logo em tempos joaninos, como um tempo de desempenhos da oficialidade mais longos e cada vez mais qualificáveis como carreiras. Quanto ao Conselho Régio, a instância política dos órgãos do poder, com actividade mais ou menos intensa, o monarca reserva-se o direito de o organizar e de designar os seus titulares. A nova dinastia irá ainda reforçar a imagem jurídica da realeza pela vertente do rei-legislador, não tanto agora pela criação como pela recolha e sistematização do Direito vigente.

The organization of bureaucratic officiality after 1383-1385 essentially reproduces what had been outlined between the $30 \mathrm{~s}$ and the 70 s of the 14th Century. When it comes to specific officers, the scene differs, since there is an obvious renewal of bureaucrats, mainly clerics and lawmen. The 15th Century will be, already in the days of King John I, a time when official status is held longer, being increasingly categorized as careers. As for the Royal Council, the king reserves to himself the right to organize the political level of the governmental organs (of more or less intense activity), and to appoint their members. The new dynasty will also reinforce the legal image of royalty, through idea of King-legislator, not so much as the result of creation, as of collection and systematization of the law in force. 
ÍNDICE

Keywords: Royal bureaucracy, Royal Council, Legislative codes, Jurists

Palavras-chave: Burocracia régia, Conselho Régio, Códigos legislativos, Legistas

\section{AUTOR}

\section{ARMANDO LUÍS DE CARVALHO HOMEM}

Universidade do Porto, Faculdade de Letras, Departamento de História e de Estudos Políticos e Internacionais; Universidade do Porto, Centro de Estudos de População, Economia e Sociedade; Universidade Autónoma de Lisboa, Centro de Investigação em Ciências Históricas 4099-002 Porto; 1169-023 Lisboa, Portugal. almisch@gmail.com. https://orcid.org/0000-0001-9337-6995. 